\title{
Prevalence and Causes of Functional Low Vision and Implications for Services: The Pakistan National Blindness and Visual Impairment Survey
}

\author{
Shabeen P. Shab, ${ }^{1}$ Hasan Minto, ${ }^{2}$ Mohammad Z. Jadoon, ${ }^{3}$ Rupert R. A. Bourne, ${ }^{1}$ \\ Brendan Dineen, ${ }^{1}$ Clare E. Gilbert, ${ }^{1}$ Mohammad D. Khan, ${ }^{3}$ on behalf of the \\ Pakistan National Eye Survey Study Group ${ }^{4}$
}

Purpose. To determine the prevalence and causes of functional low vision (FLV) and total blindness and to estimate the assessment needs for low-vision services in Pakistan.

Methods. Multistage, cluster random sampling was used to select a nationally representative sample of adults (age, $\geq 30$ years). Participants underwent visual acuity measurement and detailed ophthalmic examination. Functional low vision was defined as a corrected visual acuity in the better eye of less than $6 / 18$ to more than no perception of light (NPL) in individuals with untreatable causes of visual loss. Total blindness was defined as NPL in both eyes. Needs assessments were categorized into three groups: optical services, nonoptical/ environmental interventions, and rehabilitation.

Results. A sample of 16,507 adults ( $95.3 \%$ response rate) was examined. The standardized prevalence of FLV and total blindness were $1.7 \%$ (95\% CI: $1.5 \%-1.9 \%)$ and $0.2 \%$ (95\% CI: $0.1 \%-$ $0.2 \%$ ), respectively. More than $90 \%$ of those with FLV were illiterate and $35.3 \%$ were of working age (i.e., $<60$ years). An estimated 727,000 (586,000-891,000) adults in Pakistan had FLV. Retinal conditions were the commonest cause in urban populations $(39.8 \%$ vs. $26.5 \%$ rural) compared with corneal opacity in rural areas ( $38.0 \%$ vs. $25.5 \%$ urban). It was estimated that 565,000 adults require assessment for optical services, 735,000 for nonoptical interventions, and 424,000 for rehabilitation.

From the ${ }^{1}$ International Centre for Eye Health, London School of Hygiene and Tropical Medicine, London, United Kingdom; ${ }^{2}$ Sightsavers International, Pakistan Office, Peshawar, Pakistan; and the ${ }^{3}$ Pakistan Institute of Community Ophthalmology, Kyber Institute of Ophthalmic Medical Sciences, Peshawar, Pakistan.

${ }^{4}$ Study group members are listed in the Appendix

Supported by the International Blindness Prevention Collaborative Group which consists of The Government of Pakistan, the World Health Organization East Mediterranean Regional Office and Pakistan Office, Sightsavers International, Christoffel Blinden Mission, and the Fred Hollows Foundation. Heidelberg Engineering (Heidelberg, Germany) kindly lent two HRT-II instruments and the North West Frontier Province divisions of Remington and Kobec graciously contributed the ophthalmic drugs. SPS had full access to all the data in the study and takes responsibility for the integrity of the data and the accuracy of the data analysis.

Submitted for publication May 31, 2007; revised July 6 and September 3, 2007; accepted January 21, 2008.

Disclosure: S.P. Shah, None; H. Minto, None; M.Z. Jadoon, None; R.R.A. Bourne, None; B. Dineen, None; C.E. Gilbert, None; M.D. Khan, None

The publication costs of this article were defrayed in part by page charge payment. This article must therefore be marked "advertisement" in accordance with 18 U.S.C. $\$ 1734$ solely to indicate this fact.

Corresponding author: Shaheen Shah, International Centre for Eye Health, Department of Infectious and Tropical Diseases, London School of Hygiene and Tropical Medicine, Keppel Street, London WC1 E 7HT, UK; shaheen.shah@lshtm.ac.uk.
Conclusions. As VISION 2020 enters its second 5-year phase, the provision of low-vision services and their integration into national eyecare programs is a priority. In Pakistan, planning must take account of the magnitude along with the demographic and educational characteristics of those affected. (Invest Ophthalmol Vis Sci. 2008;49:887-893) DOI:10.1167/ iovs.07-0646

A dapting to bilateral incurable visual loss involves develop$\mathbf{1}_{\text {ment of new strategies to optimize any residual vision }}$ and/or learning awareness through other senses. The goal is to equip individuals with incurable visual loss with skills and confidence so that they can function as independently as possible and to improve their quality of life. Attainment of the goal is likely to be easier if those affected can readily access comprehensive low-vision services that are designed to cater to their needs.

The nomenclature and definitions used for different levels of visual loss are confusing. The World Health Organization (WHO) ICD (International Classification of Diseases)-10 categories of visual impairment use "corrected visual acuity." "The categories are (1) moderate visual impairment from all causes ( $<6 / 18$ [20/60] to $\geq 6 / 60[20 / 200]$ in the better eye), (2) severe visual impairment from all causes $(<6 / 60$ to $\geq 3 / 60$ [20/400] in the better eye), and (3) blindness from all causes $(<3 / 60$ in the better eye). Recent consultation has recommended modification of this definition, suggesting that as corrected visual acuity does not capture the impact of refractive errors, presenting visual acuity (i.e., with distance spectacles, if usually worn) should be used in surveys, as this measure better reflects the burden of visual impairment ${ }^{2}$ and allows the prevalence of visual impairment and blindness due to uncorrected refractive errors to be estimated. In the ICD-10 classification, moderate and severe visual impairment together are called "low vision," regardless of cause. In the ICD-11 (still to be published) the term "low vision" will no longer be used, as this causes confusion with the same term used to describe individuals who might benefit from low-vision services.

The definition we have used was derived at a WHO meeting in Bangkok, Thailand, since at the time there was no definition that adequately described the level of visual loss that identified individuals who might benefit from low-vision services: "A person with low vision is one who has impairment of visual functioning even after treatment and/or standard refractive correction, and has a visual acuity of less than $6 / 18$ to perception of light (PL) in the better eye, or a visual field of less than $10^{\circ}$ from the point of fixation, but who uses, or is potentially able to use vision for the planning and/or execution of a task." 3 The explanatory notes state that this definition was designed for reporting purposes and should not be the only criterion used for eligibility for low-vision services. For clarity we have used the term "functional" low vision (FLV) for the Bangkok definition, because this term, although not used by the WHO, has been used in a report outlining the achievements of the 


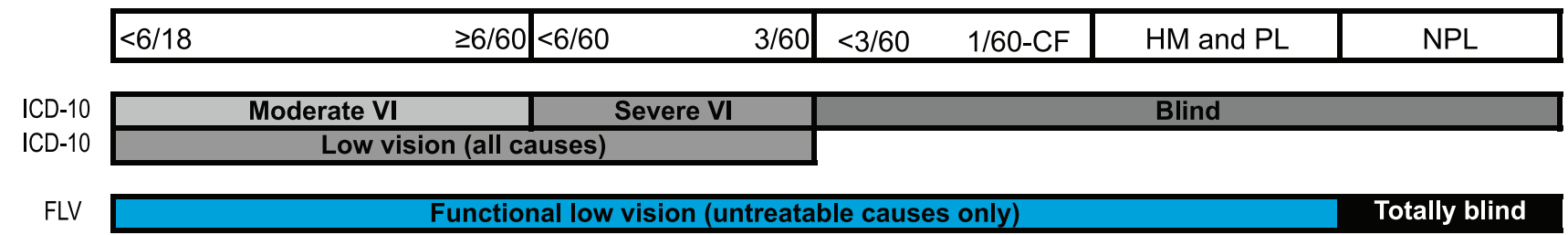

\begin{tabular}{|c|c|c|c|c|}
\hline Form vision & & Form vision & \multicolumn{2}{|c|}{ No form vision } \\
\hline $\begin{array}{l}\text { Low vision } \\
\text { service } \\
\text { components }\end{array}$ & $\begin{array}{c}\text { Optical services }+ \text { non-optical } \\
\text { interventions }\end{array}$ & $\begin{array}{c}\text { Optical services }+ \text { non-optical interventions + } \\
\text { rehabilitation }\end{array}$ & $\begin{array}{l}\text { Non-optical } \\
\text { interventions + } \\
\text { rehabilitation }\end{array}$ & $\begin{array}{l}\text { Rehabilitation } \\
\text { only }\end{array}$ \\
\hline
\end{tabular}

FIGURE 1. Definitions used in the analyses of individuals who had a corrected visual acuity of $<6 / 18$ of untreatable cause in the better eye. CF, counting fingers; VI, visual impairment; HM, hand movements; PL, perception of light; NPL, no perception of light.

first 5 years of VISION 2020. ${ }^{4}$ A graphic presentation of the different definitions and how they relate to each other is shown in Figure 1.

Provision of services for people with untreatable visual impairment, along with cataract, trachoma, onchocerciasis, childhood blindness, and refractive error, is one of the priorities of VISION 2020, the global initiative of the WHO and the International Agency for the Prevention of Blindness. However, there is a paucity of population-based research in this field, limiting estimates of the number affected worldwide. To our knowledge, the only other population-based survey that analyzed data using the FLV definition was the Andhra Pradesh Eye Disease Study (APEDS) in India. This survey showed the prevalence of FLV to be $1.05 \%$ (95\% CI: $0.82 \%-1.28 \%),{ }^{5}$ which was considerably lower than the prevalence of blindness in that population: $1.34 \%$ (95\% CI: $1.07 \%-1.61 \%){ }^{6}$ We have reported the prevalence and causes of blindness and visual impairment (using ICD-10 visual acuity categories) in a population-based survey of adults aged $\geq 30$ years in Pakistan. ${ }^{7,8}$ Just over half (51.5\%) of blindness (from all causes) was caused by cataract, with almost $75 \%$ having a treatable cause. The main cause of moderate visual impairment (from all causes) was uncorrected refractive error (42.7\%) with more than $85 \%$ having treatable causes. These causes do not form part of the calculation of FLV.

The purpose of this study was to determine the prevalence and causes of FLV, to identify socioeconomic risk factors, and to estimate national needs for the different components of care.

\section{Materials ANd Methods}

A comprehensive description of the methods used in the national blindness and visual impairment survey has been published. ${ }^{9}$ Only adults aged $\geq 30$ years were selected for the survey. A brief summary of the key methodological details is provided in the following sections.

\section{Sampling Strategy}

Multistage, stratified, cluster, random sampling, with probability proportional-to-size procedures, was adopted to select a nationally representative, cross-sectional sample of the population.

\section{Ethics and Official Government Approval for the Study}

The Pakistan Medical Research Council (PMRC) provided ethics approval. All study participants provided consent. The study protocol adhered to the tenets of the Declaration of Helsinki.

\section{Clinical Examination}

All participants, after an interview, underwent distance unaided and presenting visual acuity measurement ${ }^{10}$ with a logMAR illiterate $\mathrm{E}$ chart. Based on presenting visual acuity, participants were either marked as a "red card" (acuity $<6 / 12$ in either eye) or a "green card" ( $\geq 6 / 12$ in each eye), which defined the sequence of examinations that followed. Any participant unable to see any letters on the chart at $1 \mathrm{~m}$ was assessed to determine ability to count fingers, see hand movements, or perceive light in the relevant eye. Green-carders had an undilated ophthalmic examination. Red-carders had a more thorough examination, including retesting of best corrected visual acuity (i.e., with the results of autorefraction in trial lens frame) and a slit lamp examination with dilated indirect funduscopy.

\section{Identification of the Causes of Reduced Vision}

Causes of visual loss were determined according to WHO criteria. ${ }^{11} \mathrm{~A}$ main cause was selected for each eye, followed by selection of the main cause for the individual. The latter was based on the WHO recommendation that the cause selected should be the one "most amenable to treatment or prevention."

\section{Definitions Used in Analysis}

Functional Low Vision. Participants with FLV had (1) a best corrected distance visual acuity of $<6 / 18$ to perception of light (PL) in

TABLE 1. Participants with FLV Stratified by Gender

\begin{tabular}{|c|c|c|c|c|c|c|}
\hline & \multicolumn{2}{|c|}{ Women } & \multicolumn{2}{|c|}{ Men } & \multicolumn{2}{|c|}{ Total } \\
\hline & $n$ & $\%$ & $n$ & $\%$ & $n$ & $\%$ \\
\hline \multicolumn{7}{|l|}{ Age group (y) } \\
\hline $30-39$ & 9 & 36.0 & 16 & 64.0 & 25 & 7.3 \\
\hline $40-49$ & 26 & 63.4 & 15 & 36.6 & 41 & 12.0 \\
\hline $50-59$ & 29 & 36.7 & 26 & 63.3 & 55 & 16.0 \\
\hline $60-69$ & 43 & 54.4 & 36 & 45.6 & 79 & 23.0 \\
\hline $70+$ & 60 & 42.0 & 83 & 58.0 & 143 & 41.7 \\
\hline \multicolumn{7}{|l|}{ Province } \\
\hline Punjab & 110 & 54.7 & 91 & 45.3 & 201 & 58.6 \\
\hline Sindh & 34 & 49.3 & 35 & 50.7 & 69 & 20.1 \\
\hline NWFP & 16 & 34.8 & 30 & 65.2 & 46 & 13.4 \\
\hline Balochistan & 7 & 25.9 & 20 & 74.1 & 27 & 7.9 \\
\hline \multicolumn{7}{|l|}{ Dwelling } \\
\hline Rural & 113 & 46.3 & 131 & 53.7 & 244 & 71.1 \\
\hline Urban & 54 & 54.5 & 45 & 45.5 & 99 & 28.9 \\
\hline \multicolumn{7}{|l|}{ Education } \\
\hline Illiterate & 164 & 52.2 & 150 & 47.8 & 314 & 91.5 \\
\hline Literate & 3 & 10.2 & 26 & 89.7 & 29 & 8.5 \\
\hline Total & 167 & 48.7 & 176 & 51.3 & 343 & 100 \\
\hline
\end{tabular}

NWFP, North West Frontier Province. 


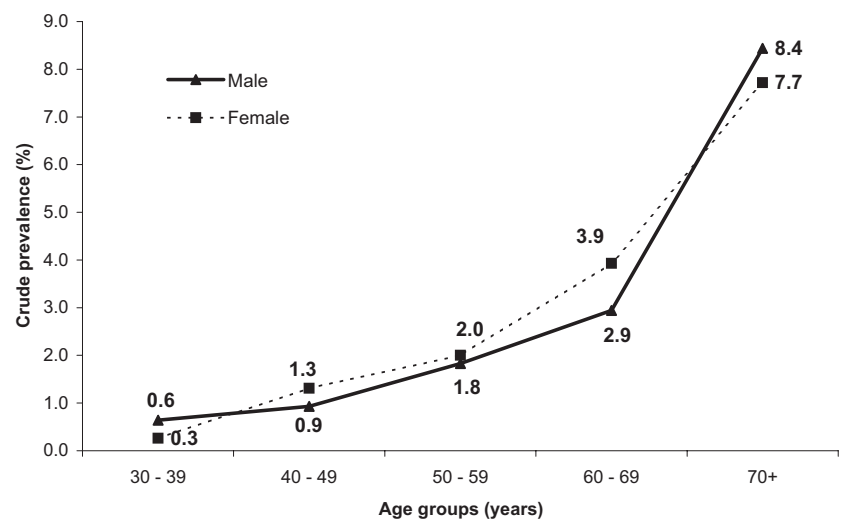

Figure 2. Age-specific prevalence of FLV in Pakistan.

the better eye, and (2) the low vision was of an untreatable cause in both eyes. Conditions considered treatable were any refractive error, cataract, and posterior capsular opacification after cataract extraction. All other causes were considered untreatable, including amblyopia (defined according to APEDS criteria). ${ }^{5}$

Totally Blind. Participants were deemed totally blind who had no perception of light (NPL) in both eyes. Adults with FLV and with total blindness were subsequently grouped into four nonmutually exclusive groups according to the services they might benefit from (i.e., optical services, nonoptical/environmental modification and rehabilitation in the form of nonvisual sensory stimulation, e.g., audio tapes; Fig. 1).

1. Participants with a best corrected vision of $<6 / 18$ to $\geq 6 / 60$ were considered to only require optical services and nonoptical interventions (e.g., environmental modification).

2. Participants with $<6 / 60$ in the better eye but who were able to read at least one letter on the logMAR chart at $1 \mathrm{~m}$ or who could count fingers in at least one eye were considered potentially able to benefit from all services.

3. Participants who could not read any letters on the chart at $1 \mathrm{~m}$ or count fingers in either eye but had at least perception of light in the better eye were categorized as potentially benefiting from nonoptical interventions (e.g., environmental modification) and rehabilitation.

4. Participants who were totally blind were categorized as requiring only rehabilitation.

Participants in groups 1and 2 were classified as having "form vision," and those in groups 3 and 4 were classified as having "no form vision."

\section{Statistical Analysis}

Data were entered into EPI INFO and transferred to a commercial software program (Stata, ver. 9.0; Statcorp, College Station, TX) for analysis. Population estimates were obtained by age and sex standardizing the prevalence using the most recent official population data for the country, ${ }^{12}$ and extrapolations to year 2020 used population estimates for Pakistan derived from the U.S. Census Bureau. ${ }^{13}$ After summary statistics and calculation of Pearson's $\chi^{2}$ statistics, associations of demographic factors with FLV were assessed using univariate, ageadjusted, and multivariable logistic regression models in a manual forward stepwise approach. Generalized estimating equations to adjust for dependency in the data due to clustered sampling were used in all models. Score tests were used to assess the significance of effects. Odds ratios (OR) and 95\% confidence intervals (CIs) are presented.

\section{RESUlts}

A sample of 16,507 (95.3\% of those enumerated) participants were examined and included in this study. Details of response rates by age and gender and reasons for nonresponse have already been published. ${ }^{7}$

Five hundred sixty-one blind individuals were identified in the survey (i.e., ICD-10 category, $<3 / 60$ presenting acuity in the better eye from all causes). With best correction and after removing those who were totally blind (i.e., bilateral NPL) and/or those who had impairment of treatable cause, 164 (29.2\%) were classified as having FLV. Similarly, according to the exclusion criteria, 31 (12.8\%) of the 243 individuals in the severe visual impairment category (i.e., ICD-10: from all causes, presenting acuity in the better eye $<6 / 60$ to $\geq 3 / 60$ ) and 148 (7\%) of the 2121 individuals with moderate visual impairment (i.e., ICD-10: from all causes, presenting acuity in the better eye

TABLE 2. Crude Prevalence of Visual Acuity Loss According to Location of Dwelling and Literacy, Stratified by Age

\begin{tabular}{|c|c|c|c|c|c|}
\hline & \multicolumn{3}{|c|}{ Form Vision } & \multicolumn{2}{|c|}{ No Form Vision } \\
\hline & $6 / 18$ to $\geq 6 / 60^{*}$ & $<6 / 60$ to $\geq 3 / 60$ & $\begin{array}{l}<3 / 60 \text { but Can See at } \\
\text { Least One Letter or } \\
\text { Count Fingers }\end{array}$ & $\begin{array}{l}\text { Cannot See Any Letters } \\
\text { on Chart or Count } \\
\text { Fingers but } \geq \mathbf{P L}\end{array}$ & Bilateral NPL \\
\hline \multicolumn{6}{|l|}{ Dwelling, rural } \\
\hline Working age* & (44) 0.54 & (4) 0.05 & (16) 0.20 & (20) 0.24 & (5) 0.06 \\
\hline Retired $\dagger$ & (73) 2.49 & (14) 0.48 & (34) 1.16 & (40) 1.36 & (22) 0.75 \\
\hline $\begin{array}{l}\text { Dwelling, urban } \\
\text { Working age* }\end{array}$ & (24) 0.56 & (1) 0.02 & (3) 0.07 & (9) 0.21 & (2) 0.05 \\
\hline Retired $\dagger$ & (34) 2.93 & (2) 0.17 & (15) 1.29 & (10) 0.86 & (3) 0.26 \\
\hline Total & (175) 1.06 & (21) 0.13 & (68) 0.41 & (79) 0.48 & (32) 0.19 \\
\hline \multicolumn{6}{|l|}{ Literate } \\
\hline Working age* & (10) 0.23 & (0) 0 & (2) 0.047 & (7) 0.16 & (2) 0.05 \\
\hline Retired $\dagger$ & (7) 1.22 & (1) 0.18 & (1) 0.17 & (1) 0.17 & (1) 0.17 \\
\hline $\begin{array}{l}\text { Illiterate } \\
\text { Working age* }\end{array}$ & (58) 0.71 & (5) 0.06 & (17) 0.21 & (22) 0.33 & (5) 0.06 \\
\hline Retired $\dagger$ & (100) 2.84 & (15) 0.42 & (48) 1.36 & (49) 1.39 & (24) 0.68 \\
\hline Total & (175) 1.06 & (21) 0.13 & (68) 0.41 & (79) 0.48 & (32) 0.19 \\
\hline
\end{tabular}

Visual acuities in the column headings are in the better seeing eye. Data are expressed by (number affected) and prevalence \%. Correction of refractive error with trial lenses based on results of autorefraction. PL, perception of light; NPL, no perception of light.

* Working age, $30-59$ years.

† Retired, $\geq 60$ years. 
TABLE 3. Causes of FLV in Pakistan

\begin{tabular}{lrrc}
\hline \multicolumn{1}{c}{ Cause } & \multicolumn{3}{c}{$\begin{array}{c}\text { Crude Prevalence \% } \\
\text { (95\% CI) }\end{array}$} \\
\hline Corneal conditions & $\boldsymbol{n}$ & $\%$ & $0.7(0.6-0.9)$ \\
Retinal diseases & 118 & 34.4 & $0.6(0.5-0.8)$ \\
Glaucoma & 104 & 30.3 & $0.3(0.2-0.3)$ \\
Amblyopia & 42 & 12.2 & $0.1(0.1-0.2)$ \\
Optic atrophy* & 15 & 4.4 & $0.1(0.1-0.2)$ \\
Phthisical & 15 & 4.4 & $0.04(0.01-0.08)$ \\
Other† & 6 & 1.8 & $0.05(0.02-0.1)$ \\
Unable to determine cause $\neq$ & 33 & 9.6 & $0.2(0.1-0.3)$ \\
Total & 343 & $100 \%$ & $2.1 \%(1.9-2.3)$ \\
\hline
\end{tabular}

* Of causes other than glaucoma.

† Congenital eye anomalies, for example.

$\ddagger$ Specific cause was not determined but participants were assumed to have untreatable disease.

$<6 / 18$ to $\geq 6 / 60$ ) were defined as having FLV. The total number of participants with FLV was therefore 343.

Among the participants with FLV, approximately half ( $n=$ $175,51 \%)$ had a best corrected visual acuity of $<6 / 18$ to $6 / 60$ in the better eye, and a further $21(6.1 \%)$ had a best corrected visual acuity of $<6 / 60$ to $3 / 60$ in the better eye. The remaining 147 (42.9\%) participants were $<3 / 60$ in the better eye, 34 of whom had NPL in one eye. One hundred sixty-seven (48.7\%) were women. The mean age of the women was 61.7 years and that of the men was 63.2 years $(P=0.38)$. Demographic distributions are shown in Table 1.

\section{Prevalence of FLV}

The crude prevalence of FLV was 2.1\% (95\% CI: 1.9-2.3). Prevalence rates stratified by age and gender are shown in Figure 2. The province of Balochistan had the highest crude prevalence of FLV (2.8\%; 95\% CI: $1.9-4.1)$ followed by Punjab (2.2\%; 95\% CI: 2.0 to $2.6 \%)$, Sindh (1.9\%; 95\% CI: $1.5-2.4)$, and North West Frontier Province (NWFP; 1.5\%; 95\% CI: 1.1-2.0). The prevalence of FLV was significantly higher in illiterate (2.7\%; 95\% CI: $2.4-3.0)$ than in literate participants $(0.6 \%$; $95 \%$ CI: $0.4-0.9, P<0.001$; Table 2 ) and was marginally higher in rural clusters $(2.2 \%$; $95 \% \mathrm{CI}: 1.9-2.5)$ than in urban clusters
(1.8\%; 95\% CI: $1.5-2.2, P=0.09)$. Only 19 adults with FLV were both literate and of working age (5.5\%).

\section{Causes of FLV}

Causes of FLV are shown in Table 3. Just over one third (34.4\%) of FLV was due to corneal opacities. Retinal conditions and amblyopia were associated with less severe visual loss than were phthisis, glaucoma, optic atrophy, and corneal diseases (Fig. 3). The main cause of FLV in NWFP and Balochistan was retinal conditions ( $47.8 \%$ and $33.3 \%$, respectively), whereas in Punjab and Sindh the main cause was corneal disease, mainly scarring (38.8\% and 33.3\%, respectively). There were significant differences between rural and urban areas. Retinal disease predominated in urban areas (39.8\% vs. $26.5 \%$ ), whereas corneal opacity was the commonest cause in rural areas $(38.0 \% \mathrm{vs}$. $25.5 \%)$. Optic atrophy was the leading cause of FLV in 30- to 39-year-olds (28\%), but was less important in older age groups.

\section{Association and Risk Factors for FLV}

Age was the most important risk factor for FLV (Table 4). There was no significant gender difference. Geographic differences were significant, with Balochistan and Punjab having higher odds of FLV than NWFP. Poor education was also significantly associated with FLV.

\section{Estimation of the Number of People with FLV in Pakistan}

Using the age and sex standardized prevalence of FLV (1.7\%; 95\% CI: 1.5-1.9) the total number of adults with FLV in Pakistan is estimated to be 727,000 (range, 586,000-891,000). Estimates at the provincial level are shown in Table 5. The number of adults with FLV will more than double by 2020, to $1,480,000$, assuming that the prevalence remains unchanged.

An all-age estimate was calculated by using statistics (of prevalence in other age groups) from APEDS reports; a prevalence of FLV of $0.3 \%$ in 0 - to 15 -year olds and $0.4 \%$ in 15 - to 30 -year-olds. ${ }^{5}$ The all-age prevalence in Pakistan is estimated to be $0.8 \%$.

\section{Totally Blind: Bilateral NPL}

Thirty-two participants ( 15 women) were identified as totally blind; $84.4 \%$ were living in rural areas, 20 (62.5\%) were over 70

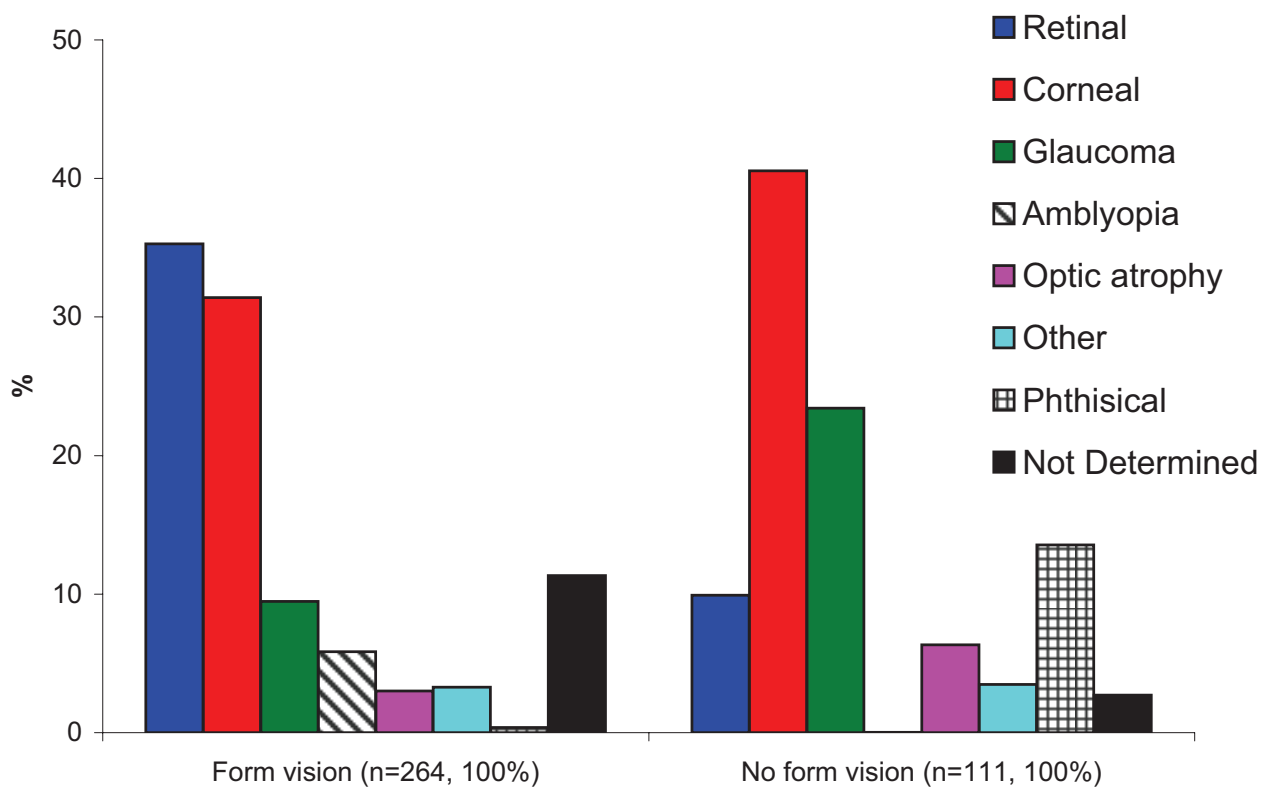

Figure 3. Causes of FLV and total blindness in participants by presence and absence of form vision. Form vision: best corrected visual acuity of $<6 / 18$ of untreatable cause, with those with the lowest levels of acuity being able to discriminate at least one letter at $1 \mathrm{~m}$ or count fingers at $1 \mathrm{~m}$. No form vision: participants unable to discriminate one letter at $1 \mathrm{~m}$ or count fingers at $1 \mathrm{~m}$. Not determined: participants in whom a specific cause was not determined but untreatable disease was inferred from examination. 
TABLE 4. Association Analysis of Participants with FLV

\begin{tabular}{|c|c|c|c|c|}
\hline & $n$ & $\begin{array}{c}\text { Univariate } \\
\text { Analysis OR } \\
(95 \% \text { CI) }\end{array}$ & $\begin{array}{c}\text { Age-Adjusted } \\
\text { OR }(95 \% \mathrm{CI})\end{array}$ & $\begin{array}{l}\text { Adjusted OR* } \\
\text { (95\% CI);P }\end{array}$ \\
\hline \multicolumn{5}{|l|}{ Age $(y)$} \\
\hline $30-49$ & $25 / 5,955$ & 1 & 1 & 1 \\
\hline $40-49$ & $41 / 3,589$ & $2.7(1.7-4.5) \dagger$ & $2.7(1.7-4.5) \dagger$ & $2.6(1.6-4.3)<0.001$ \\
\hline $50-59$ & $79 / 2,870$ & $4.6(2.9-7.5) \dagger$ & $4.6(2.9-.5) \dagger$ & $4.3(2.6-6.9)<0.001$ \\
\hline $60-69$ & $79 / 2,345$ & $8.4(5.3-13.2) \dagger$ & $8.4(5.3-13.2) \dagger$ & $7.1(4.5-11.2)<0.001$ \\
\hline $70+$ & $143 / 1,748$ & $20.9(13.7-32.2) \dagger$ & $21.0(13.7-32.3) \dagger$ & $17.0(11.0-26.3)<0.001$ \\
\hline \multicolumn{5}{|l|}{ Gender } \\
\hline Female & $167 / 8,766$ & 1 & 1 & \\
\hline Male & $176 / 7,741$ & $1.2(0.9-1.5)$ & $1.0(0.8-1.2)$ & \\
\hline \multicolumn{5}{|l|}{ Province } \\
\hline NWFP & $46 / 3,094$ & 1 & 1 & 1 \\
\hline Balochistan & $27 / 945$ & $1.9(1.2-3.2) \dagger$ & $2.2(1.3-3.5) \dagger$ & $2.1(1.3-3.4) 0.003$ \\
\hline Punjab & $201 / 8,804$ & $1.5(1.1-2.1) \dagger$ & $1.5(1.1-2.1) \dagger$ & $1.6(1.1-2.1) 0.007$ \\
\hline Sindh & $69 / 3,664$ & $1.3(0.9-1.9)$ & $1.3(0.9-1.9)$ & $1.4(0.9-2.0) 0.1$ \\
\hline \multicolumn{5}{|l|}{ Location } \\
\hline Urban & $99 / 5,423$ & 1 & 1 & \\
\hline Rural & $244 / 11,084$ & $1.2(1.0-1.6) \dagger$ & $1.1(0.8-1.4)$ & \\
\hline \multicolumn{5}{|l|}{ Education } \\
\hline None & $314 / 11,586$ & 1 & 1 & 1 \\
\hline Primary & $5 / 1,429$ & $0.1(0.1-0.3) \dagger$ & $0.2(0.1-0.4) \dagger$ & $0.2(0.1-0.4)<0.001$ \\
\hline Higher $\neq$ & $24 / 3,488$ & $0.2(0.2-0.4) \dagger$ & $0.5(0.3-0.7) \dagger$ & $0.5(0.3-0.7)<0.001$ \\
\hline
\end{tabular}

* Multivariate logistics regression model including age, province and school attendance.

† Statistically significant at $P<0.05$.

$\neq$ Includes all participants who attended school beyond primary school.

years of age, and $90.6 \%$ were uneducated. Corneal opacities and phthisis bulbi (31.3\%) and glaucoma (28.1\%) were the commonest causes. The age- and sex-adjusted prevalence of total blindness in adults in Pakistan was 0.2\% (95\% CI: 0.1-0.2).

\section{National Requirement for Assessments}

An estimated 1,725,000 assessments are needed for adults who have FLV or who are totally blind in Pakistan. The national assessment needs are shown in Table 6.

\section{Discussion}

The Pakistan National Blindness and Visual impairment Survey is the largest and most comprehensive population-based eye survey to be conducted in Pakistan, a country of nearly 150 million people. The standardized prevalence of blindness (ICD10 , presenting $<3 / 60$ better eye from all causes) in adults and all age groups were $2.7 \%$ and $0.8 \%$, respectively. ${ }^{7}$ The standardized prevalence of FLV in adults and in all age groups in this survey were $1.7 \%$ and $0.8 \%$, respectively. The ratio of blindness to FLV in Pakistan is therefore 1.6:1 in adults and 1:1 in all age groups. The blindness-to-FLV ratio in APEDS, the only other survey to use the same definitions, was 1.3:1. ${ }^{5}$ Both surveys, finding the prevalence of blindness to be higher than the prevalence of FLV, tend to agree with an approximation "rule of thumb" suggested by experts at a WHO meeting in Hong Kong. In their report it was suggested, where data on the

TABLE 5. Estimated Magnitude of FLV in Adults in Pakistan in 2003

\begin{tabular}{lcc}
\hline Province & $\begin{array}{c}\text { Estimated Number } \\
\text { with FLV }\end{array}$ & $\mathbf{9 5 \%}$ CI \\
\hline Punjab & 483,000 & $413,000-559,000$ \\
Sindh & 132,000 & $96,000-171,000$ \\
NWFP & 73,000 & $52,000-98,000$ \\
Balochistan & 39,000 & $25,000-63,000$ \\
Total & 727,000 & $586,000-891,000$ \\
\hline
\end{tabular}

prevalence of FLV are not available, that $95 \%$ of the prevalence of blindness be used to estimate the prevalence of FLV. ${ }^{14}$ Application of this rule shows that there are approximately 35 million people worldwide with FLV; however, more data are needed on the prevalence of FLV in different populations to refine this estimate.

In this study the need for services was categorized into four components based purely on distance visual acuity. In reality, the delivery of low-vision services should be needs based, multidisciplinary, and flexible, focusing on improving functional abilities. For example, an individual whose employment depends on reading small print has different requirements than does someone who is illiterate but who wants to continue farming or attending social functions. The optimal low-vision team comprises eyecare personnel, occupational therapists, adaptive technology specialists, teachers, audiologists and members of the social services and state blind societies. The mutual goal of these groups is to provide appropriate equipment together with specific orientation and training to allow the individual to maintain independence. In general, optical devices (including distance or near magnifiers, field expanders, night-vision aids) are less useful for those with poorer levels of visual function, and those affected require environmental modification (e.g., light augmentation, improving mobility). Individuals with very poor or no visual function will require rehabilitation including sensory substitution (accessing information via tactile or auditory methods). The results of this survey indicate that in Pakistan, 565,000 individuals need assessment for optical services, 735,000 need assessment for nonoptical interventions, and 424,000 need assessment for rehabilitation. As indicated earlier, the definition of FLV vision used in this article should not be the sole eligibility criteria for low-vision services, as others may also have the potential to benefit.

In our study, corneal disease accounted for more than one third of those with FLV and for just over 4 in 10 with no form vision. Comparison with APEDS data, where retinal diseases were the commonest cause, is limited, as individuals with corneal scarring considered treatable through corneal grafting 
TABLE 6. Estimated Number of Adults with FLV Who May Benefit from the Different Components of Low-Vision Services in Pakistan

\begin{tabular}{|c|c|c|c|c|}
\hline Visual Acuity & $\begin{array}{l}\text { Age and Sex } \\
\text { Standardized } \\
\text { Prevalence } \\
(\%)\end{array}$ & $\begin{array}{l}\text { Optical Services } \\
\text { (Score) }\end{array}$ & $\begin{array}{c}\text { Nonoptical } \\
\text { Interventions } \\
\text { (e.g., Environmental } \\
\text { Modification) }\end{array}$ & Rehabilitation \\
\hline$<6 / 18-6 / 60$ & 0.9 & $381,000(+++)$ & $381,000(+++++)$ & - \\
\hline$<6 / 60-<3 / 60$ & 0.1 & $43,000(+++++)$ & $43,000(+++++)$ & $43,000(++)$ \\
\hline $\begin{array}{l}<3 / 60 \text {; can see at least one letter or can count } \\
\text { fingers }\end{array}$ & 0.3 & $141,000(++)$ & $141,000(+++++)$ & $141,000(++++)$ \\
\hline $\begin{array}{l}\text { Cannot see any letters on chart or count fingers but } \\
\geq \mathrm{PL} \text { ) }\end{array}$ & 0.4 & - & $170,000(+)$ & $170,000(+++++)$ \\
\hline NPL in both eyes & 0.2 & - & - & $70,000(+++++)$ \\
\hline Total & & 565,000 & 735,000 & 424,000 \\
\hline
\end{tabular}

Estimated numbers are not mutually exclusive of one another by columns. These data should be used for planning services rather than for determining eligibility for the different components of care. + , Score of a possible 5 indicating the potential benefit.

were excluded from the definition in that study. In contrast corneal disease was included in our definition of FLV. Although the large proportion of corneal scarring due to trachoma, vitamin A deficiency, and trauma, ${ }^{15}$ is avoidable, the results of treatment by corneal transplantation are often poor in these settings. ${ }^{16}$ Furthermore in Pakistan, corneal grafting is currently not a viable option for most of those afflicted.

Although the survey was conducted with rigorous methodology and after extensive training, there are some limitations as far as FLV is concerned. For logistic reasons perimetry was conducted only on a selected subgroup which may have led to underascertainment of individuals defined as having FLV on the basis of visual field loss alone (e.g., from glaucoma or retinitis pigmentosa). In addition, visual needs cannot be assessed by distance visual acuity alone and other tests of visual function are necessary (e.g., near vision, contrast sensitivity). These were not performed, as FLV was not a primary outcome of this survey.

Although evidence exists that low-vision services improve quality of life and mental state ${ }^{17-19}$ clinical trial evidence of the effectiveness of specific interventions for individuals with FLV is lacking. ${ }^{20} \mathrm{~A}$ recent Cochrane review concluded that further research is recommended to compare different types of lowvision devices as well as to delineate patient characteristics that predict performance. ${ }^{21}$ Designing clinical trials of low-vision interventions is challenging due to the heterogeneous nature of the causes and consequences of the conditions causing FLV, the wide range of possible interventions, the fact that interventions must be tailored to individuals' needs, and the large number of possible outcomes (McGuire MG. IOVS 2005;44: ARVO E-Abstract 2267). Research of this kind is urgently needed in developing counties, as findings from studies in industrialized countries may not apply in situations in which the causes and functional visual needs are quite different.

As VISION 2020 enters its second 5-year phase the provision of low-vision services and their integration into national eyecare programs is a high priority, as this has been a neglected area in the past. For example, a recent survey throughout India showed that only $48(6.8 \%)$ of 701 eyecare institutions had a dedicated low-vision service. ${ }^{22}$ The report concluded that lowvision services were less well developed than those for children. Lack of training and knowledge (82.3\%) and of awareness (74.7\%) were the perceived barriers to provision of these services. $^{23}$

In conclusion, population-based data on the prevalence and causes of untreatable visual impairment (i.e., FLV) are scarce but critically important for planning low-vision services. ${ }^{24}$ This global information gap should be addressed as should awareness of the definition of FLV. The definition used in our study should not be regarded as a replacement for the ICD categories of blindness and visual impairment, as the ICD categories provide population-based data for planning clinical eyecare services, whereas the FLV definition provides data for providing service for the needs of the untreatably impaired.

The Pakistan government's 5-year national plan for the prevention of blindness includes development of low-vision services at each level of service delivery in each province. At the primary level, activities include training instructors and classroom teachers in orientation and mobility and developing outreach programs. At the secondary level, the plan includes development of new low-vision clinics and resource centers, with one tertiary-level, low-vision service with early-intervention clinics in each province. Implementation should allow for the current backlog of patients requiring assessment and services, bearing in mind the anticipated doubling by 2020 of those affected. Planning also should take account of the fact that the overwhelming majority (91.5\%) of people with FLV identified in this survey were illiterate, only $35.3 \%$ were of working age, and only $5.5 \%$ were both literate and of working age.

\section{Acknowledgments}

The authors thank Tauqeer Abbas and Fakhre-e Alam for data entry; Mahwash Akhtar-Khan, Yelena Alexander, and Rahul Shah for assisting in data cleaning; Fazl-Subhan for assisting with financial management; and Lateef Brothers and S. Haji Ameerdin and Sons, both based in Lahore, Pakistan, for generous instrument support.

\section{References}

1. World Health Organization. ICD-10 International Statistical Classification of Diseases and Related Health Problems, 10th Revision In: Johnson GJ, Minassian DC, Weale R, eds. The Epidemiology of Eye Disease. London: Chapman \& Hall Medical; 1998:8-30.

2. World Health Organization. Consultation on Development of Standards for Characterization of Visual Loss and Visual Functioning. Geneva, Switzerland: WHO; 2003:PBL/03.91.

3. World Health Organization. The Management of Low Vision in Children. Report of a WHO Consultation: Bangkok, July 1992. Geneva, Switzerland: WHO; 1993:PBL/93.27.

4. World Health Organization /International Agency for the Prevention of Blindness. State of the World's Sight Vision 2020: The Right to Sight 1999-2005. Geneva, Switzerland: WHO; 2005.

5. Dandona R, Dandona L, Srinivas M, Giridhar P, Nutheti R, Rao GN. Planning low vision services in India: a population-based perspective. Ophthalmology. 2002;109(10):1871-1878.

6. Dandona L, Dandona R, Srinivas M, et al. Blindness in the Indian state of Andhra Pradesh. Invest Ophthalmol Vis Sci. 2001;42(5): 908-916.

7. Jadoon Z, Dineen B, Bourne RRA, et al. Prevalence of blindness and visual impairment in Pakistan. The Pakistan National Blindness and 
Visual impairment Survey. Invest Ophthalmol Vis Sci. 2006; 47(11):4749-4755.

8. Dineen B, Bourne RR, Jadoon Z, et al. Causes of blindness and visual impairment in Pakistan. The Pakistan National Blindness and Visual Impairment Survey. Br J Ophthalmol. 2007;01:1005-1010.

9. Bourne R, Dineen B, Jadoon Z, et al. The Pakistan National Blindness and Visual Impairment Survey research design, eye examination methodology and results of pilot study. Ophthalmic Epidemiol. 2005:12(5):321-333.

10. Rosser DA, Laidlaw DA, Murdoch IE. The development of a "reduced logMAR" visual acuity chart for use in routine clinical practice. Br J Ophthalmol. 2001;85(4):432- 436.

11. World Health Organization. Coding instructions for the WHO/PBL eye examination record (Version III). Geneva, Switzerland: WHO; 1988:PBL/88.1.

12. Pakistan Demographic Survey. Islamabad, Pakistan: Federal Bureau of Statistics; 2003. Available at http://www.statpak.gov.pk. Accessed May 2007.

13. International Data Base. Washington, DC: U.S. Census Bureau, Population Division, International Programs Center. Available at http://www.census.gov/cgi-bin/ipc/idbsum.pl?cty $=$ PK. Accessed May 2007.

14. World Health Organization. Asia Pacific Low Vision Workshop, Hong Kong. 2001; Geneva, Switzerland: WHO; 2002;PBL/02.87 HK.

15. Whitcher JP, Srinivasan M, Upadhyay MP. Corneal blindness: a global perspective (review). Bull World Health Organ. 2001; 79(3):214-221.

16. Garg P, Krishna PV, Stratis AK, Gopinathan U. The value of corneal transplantation in reducing blindness. Eye. 2005;19(10):11061114.

17. Vijayakumar V, John RK, Datta D, Thulasiraj RD, Nirmalan PK. Quality of life after community-based rehabilitation for blind persons in a rural population of South India. Indian J Ophthalmol. 2004;52(4):331-335.

18. Lamoureux EL, Pallant JF, Pesudovs K, Rees G, Hassell JB, Keeffe JE. The effectiveness of low-vision rehabilitation on participation in daily living and quality of life. Invest Ophthalmol Vis Sci. 2007; 48(4): 1476-1482.

19. Horowitz A, Reinhardt JP, Boerner K. The effect of rehabilitation on depression among visually disabled older adults. Aging Ment Health. 2005 Nov;9(6):563-570.

20. Reeves BC, Harper RA, Russell WB. Health Services Research Unit, London School of Hygiene, UK Enhanced low vision rehabilitation for people with age related macular degeneration: a randomised controlled trial. Br J Ophthalmol. 2004;88(11):1443-1449.

21. Virgili G, Acosta R. Reading aids for adults with low vision. Cochrane Database Syst Rev. 2006;18(4):CD003303.

22. Department of Community Ophthalmology. Human Resources and Infrastructure for Control Childhood and Corneal Blindness and Low Vision Services in India. New Delhi, India: Dr Rajendra Prasad Centre for Ophthalmic Sciences; 2006;90-1.

23. Khan SA, Shamanna B, Nuthethi R. Perceived barriers to the provision of low vision services among ophthalmologists in India. Indian J Ophthalmol. 2005;3(1):69-75.

24. Culham LE, Ryan B, Jackson AJ, et al. Low vision services for vision rehabilitation in the United Kingdom. Br J Ophthalmol. 2002; 86(7):743-747.

\section{APPENDIX}

\section{Pakistan National Eye Survey Study Group}

Shad Mohammed, Zia Uddin Sheik, Asad Aslam, Nasim Panazai, Shabbir Mir Niaz Ali, Pak Sang Lee (Technical Coordinator, International Centre for Eye Health, London), Ikram Ullah Khan (Biomedical Engineer, Pakistan Institute of Community Ophthalmology), Haroon Awan (Sight Savers International), Rubina Gillani (Fred Hollows Foundation), Babar Qureshi (Christoffel Blindenmission), Mohammed Shabbir and Falak Naz (Clinical and Community Ophthalmologists, respectively, North West Frontier Province team), Abdul Ghafoor and Kiramatullah (Survey Ophthalmologists, Punjab and Baluchistan Teams), Waheed Shaikh and Amjad Shaikh (Survey Ophthalmologists, Sindh Team).

\section{$\begin{array}{lllllll}\mathbf{E} & \mathbf{R} & \mathbf{R} & \mathbf{A} & \mathbf{T} & \mathbf{U} & \mathbf{M}\end{array}$}

Erratum in: "Photoreceptor Protection against Light Damage by AAV-Mediated Overexpression of Heme Oxygenase-1" by Sun et al. (Invest Ophthalmol Vis Sci. 2007;48:5699-5707.)

In the footnotes, the first author affiliation should be: "1Department of Ophthalmology, Chang Gung Memorial Hospital, Taoyuan, Taiwan.” 